\title{
Impact of Divorce and Separation for the Women with Spinal Cord Injury in Community Reintegration
}

\author{
Farjana Taoheed, Md. Obaidul Haque, Shamima Islam Nipa, Rakib Husain, \\ Muhammad Millat Hossain, Apurbo Roy, and Md. Shahoriar Ahmed
}

\section{ABSTRACT}

Introduction: Marriage is a lawful agreement between a man and woman. They can share their rights and responsibilities under the provision of Law, whereas divorce or separation is dissolving these bonds between married couples. Among Spinal Cord Injury patients this divorce or separation rate is high in Bangladesh.

Objectives: The main aim of this study was to identify the impacts of divorce and separation for the women with spinal cord injury during community reintegration.

Methodology: This was a mixed-method-type of study where the participant's demographics data were analyzed by quantitative analysis by using a standard developed questionnaire (CIQ-R) and semi-structured open ended questionnaire to explore the best possible feedback from the participants for maximum 25-minutes duration. The present study conducted with 39 women participants since July 2011 to June 2016 at the CRP. Data were analyzed by SPSS 20 version.

Result: Total community integration score was 12.03 and SD was \pm 3.87 . This score was significantly lower to compare other study for person with SCI. The mean and SD of home integration $(2.89, \pm 1.53)$, social integration $(3.74, \pm 1.16)$, productivity $(3.12, \pm 1.81)$ and electronic social networking $(2.54, \pm 1.86)$ scores were also lower than the other study. Age, education, occupation, religion, living area, monthly income, marriage before or after injury, duration of marriage, number of children, duration of divorce or separation, ASIA, neurological level was found to be significant predictors of divorce or separation. Four major themes were found in this study (1) Causes of divorce and separation (2) Impact on relationship with family member (3) Impact on social participation (4) Impact on productive activities. Regardless of all participants reported loss of autonomy and functional ability, loss of sex life, loss of self-identity, loss of intimacy within laws, loss of autonomy were the main causes of divorce and separation.

Conclusion: Participants scored low in total community integration was lower than compare to other. Suggesting there is a great need to develop interventions by governmental and non-governmental organizations to better integrate individuals of women with divorce and separation with spinal cord injury in the community.

Keywords: Spinal Cord Injury, Women, Divorce, Separation, Community Integration.

\section{INTRODUCTION}

Spinal Cord Injury (SCI) is medically complex, life changing, devastating condition where a person' requires a bio-psychosocial adaptation [1]. Women with spinal cord injury suffers a lot to make her consistent with adaptive changes and it is no more surprise that couple undergoes a lot of pressure after injury. A married women always think about her family dynamics as well as try to maintain the equality within the relationship [2]. However, lack of community access, confidence and self-privacy act as the major problem
Submitted : January 25, 2021

Published : March 15, 2021

ISSN: $2593-8339$

DOI: $10.24018 /$ ejmed.2021.3.2.690

Farjana Taoheed *

Department of Physiotherapy, Centre for the Rehabilitation of the Paralysed (CRP), Dhaka, Bangladesh.

(e-mail: farjana.taoheed@ gmail.com) Md. Obaidul Haque

Department of Physiotherapy, Bangladesh Health Professions Institute (BHPI), Bangladesh.

(e-mail: physioobaid@gmail.com)

Shamima Islam Nipa

Department of Rehabilitation Science, Bangladesh Health Professions Institute (BHPI), c Dhaka, Bangladesh.

(e-mail: shamimamrs2017@gmail.com) Rakib Husain

Department of Occupational Therapy, Centre for the Rehabilitation of the Paralysed (CRP), Dhaka, Bangladesh.

(e-mail: husain_bd@yahoo.com)

Muhammad Millat Hossain

Department of Rehabilitation Science, Bangladesh Health Professions Institute (BHPI), Centre for the Rehabilitation of the Paralysed (CRP), Dhaka, Bangladesh.

(e-mail: millatcbr@ yahoo.com)

Apurbo Roy

Department of Physiotherapy, Centre for the Rehabilitation of the Paralysed (CRP), Dhaka, Bangladesh.

(e-mail: apurbobinaroy@gmail.com)

Md. Shahoriar Ahmed

Bangladesh Physiotherapy Association (BPA), Bangladesh.

(e-mail: physio.shahoriar@gmail.com)

*Corresponding Author 
divorce compared with the general population [7]. However, very few articles conducted about the perspectives of people with SCI toward marriage [8]. The estimation of divorce rate after SCL has been reported to be 1.5-2.5 times higher than that general population [9]. Several study showed that, higher divorce rate occurs mostly in the first three years after SCL [9]. As per previous study, 20\% separation or divorce occurs within five years of injury [10]. The marital status of female with SCI is more affected than the male with SCI [11]. Most of the divorce of SCL patients' occur within five years and within two years $20 \%$ were separated and $26.1 \%$ were divorced from their spouse according to [12], $48 \%$ of SCI participants had divorced or separated after injury. Therefore the aim of the current study was to explore the impact of divorce and separation in community reintegration of the SCL women.

\section{METHODS AND MATERIALS}

\section{A. Study Settings and Participants}

The current study was a mixed-method-type of study where the participant's demographics data were analyzed by quantitative analysis. In this study a total 39 women with SCI participants participated since July 2011 to June 2016 at the Centre for the Rehabilitation of the Paralysed (CRP). Only married women with divorce and separation status have included in this research.

\section{B. Measurements}

A standard developed questionnaire (CIQ-R) and semistructured open ended pretested questionnaire used to explore the best possible feedback from the participants.

\section{Statistical Analysis}

The Qualitative data were analyzed by Qualitative content analysis (QCA) and it perform by taking statement from the participants with detailed information and then coding it, categorized and generate the theme. According to the categorization all the information has been inputted. After finding the specific tabulation of coding researcher finds the important codes and made the projected themes for this study. All the data inputted appropriately. The quantitative data were analyzed by SPSS version 16 [13].

\section{RESULTS}

The questionnaire of CIQ-R, it had four part. From the analysis of the data of of this four part like home integation, social integation, productivity and electronic social networking of the participants, it was identified that among the $(n=39)$ participants the mean home integration was 2.89 and SD was \pm 1.53 . The second part was social integration and its mean and SD was 3.74 and \pm 1.61 . The third part was productive activities and its mean and SD was $3.12, \pm 1.81$ the last part of this questionnaire was electronic social networking. And its mean and SD was $2.54, \pm 1.86$. From the analysis of this data, it could be assumed that the data are valid data, because all SD was less than half of the mean.

Causes of Divorce and Separation

Loss of autonomy and functional ability $(n=8,66.67 \%)$
TABLE 1: DEMOGRAPHIC DISTRIBUTION OF THE PARTICIPANTS

\begin{tabular}{|c|c|c|}
\hline Traits & Frequency $(\mathrm{n})$ & Percentage $(\%)$ \\
\hline \multicolumn{3}{|c|}{ Total number of women n: $284(15.09 \%)$} \\
\hline Tetraplegia & 106 & $37.32 \%$ \\
\hline Paraplegia & 177 & $62.32 \%$ \\
\hline Head Injury & 3 & $1.05 \%$ \\
\hline \multicolumn{3}{|c|}{ Age distribution, mean (31.62) } \\
\hline $16-26 y$ & 7 & $17.9 \%$ \\
\hline $27-37 y$ & 25 & $64.1 \%$ \\
\hline $38-48$ y & 6 & $15.4 \%$ \\
\hline $49-59 y$ & 1 & $2.6 \%$ \\
\hline \multicolumn{3}{|c|}{ Educational status } \\
\hline Illiterate & 19 & $48.7 \%$ \\
\hline Class I to V & 5 & $12.8 \%$ \\
\hline Class VI to $\mathrm{X}$ & 8 & $20.5 \%$ \\
\hline Passed SSC $\backslash$ Equivalent & 3 & $7.7 \%$ \\
\hline Pass HSC \Equivalent & 3 & $7.7 \%$ \\
\hline Graduate $\backslash$ Equivalent & 1 & $2.6 \%$ \\
\hline \multicolumn{3}{|c|}{ Occupation } \\
\hline Unemployed & 30 & $76.9 \%$ \\
\hline Service holder & 3 & $7.7 \%$ \\
\hline Business & 5 & $12.8 \%$ \\
\hline Retired & 1 & $2.6 \%$ \\
\hline \multicolumn{3}{|c|}{ Monthly income } \\
\hline 1-5000 BDT & 25 & $64.1 \%$ \\
\hline 5001-10000 BDT & 13 & $33.3 \%$ \\
\hline 10001-20000 BDT & 1 & $2.6 \%$ \\
\hline \multicolumn{3}{|c|}{ Living location } \\
\hline Rural & 29 & $74 \%$ \\
\hline Urban & 10 & $26 \%$ \\
\hline \multicolumn{3}{|c|}{ Number of children } \\
\hline $1-2$ & 24 & $61.5 \%$ \\
\hline $3-4$ & 13 & $33.3 \%$ \\
\hline 5to above & 2 & $5.1 \%$ \\
\hline \multicolumn{3}{|c|}{ Duration of divorce or separation } \\
\hline $1-2$ years & 11 & $23.1 \%$ \\
\hline $3-4$ years & 8 & $17.9 \%$ \\
\hline $5-6$ years & 14 & $28.2 \%$ \\
\hline $7-8$ years & 5 & $12.8 \%$ \\
\hline 9 to above years & 1 & $17.9 \%$ \\
\hline \multicolumn{3}{|c|}{ Marriage before or after injury } \\
\hline Before Injury & 35 & $89.7 \%$ \\
\hline After Injury & 4 & $10.3 \%$ \\
\hline \multicolumn{3}{|c|}{ Duration of marriage } \\
\hline $1-3$ years & 14 & $35.9 \%$ \\
\hline $4-8$ years & 15 & $38.5 \%$ \\
\hline 9 years to above & 10 & $25.6 \%$ \\
\hline \multicolumn{3}{|c|}{ ASIA } \\
\hline Complete A & 22 & $56.4 \%$ \\
\hline Incomplete B & 10 & $20.5 \%$ \\
\hline Incomplete $\mathrm{C}$ & 2 & $10.3 \%$ \\
\hline \multirow{2}{*}{\multicolumn{3}{|c|}{ Neurological level }} \\
\hline & & \\
\hline Thoracic (T1-T6) & 4 & $23 \%$ \\
\hline Thoracic (T7-T12) & 28 & $49 \%$ \\
\hline Lumbar(L1-L2) & 7 & $28.2 \%$ \\
\hline
\end{tabular}

TABLE 2: MEAN AND SD OF HOME INTEGRATION, SOCIAL INTEGRATION, PRODUCTIVITY AND ELECTRONIC SOCIAL NETWORKING AMONG

\begin{tabular}{cc}
\multicolumn{2}{c}{ PARTICIPANTS } \\
\hline Components & Mean, Standard Deviation \\
\hline Home Integration & $2.89, \pm 1.53$ \\
Social Integration & $3.74, \pm 1.61$ \\
Productive Activities & $3.12, \pm 1.81$ \\
Electronic Social Networking & $2.54, \pm 1.86$ \\
\hline Total CIQ & $12.03, \pm 3.87$ \\
\hline
\end{tabular}

Almost every participant thinks that the main reasons of their marital disharmony are loss of anatomy and lessen functional ability. Among the 12 respondent's, 8 participants think that, reduce of working ability is one of another cause of their divorce or separation. One person said that 'I'm in a wheelchair, but that was not my only problem. I have no feeling on my both legs and even I can't control my urination and so many other things". Other one stated that "if I had 
ability to move my both leg and I would be able to do anything like before my husband had not leave me like that". In addition, another ones opinion was "I was the key person for doing household activities. But now even I cannot do my own work only". It was stated by one participant that "No one likes that person who is not productive for family. Now I can't move my legs and I can't do any difficult work. Sometimes I need help from other to do my own work".

\section{Loss of sex life $(n=11,91.67 \%)$}

Most of the participants (11) had given priority about sexual relationship in their conjugal life. They thought that without sex, conjugal life does not exist. They also realized that, their husbands considered them unable to have sex after their disability. One stated that "I had tried several times to stay with my husband after my injury. But every time he refused me". It was expressed by one participant that "the sex was a very, very important part of our married life and from that I felt it changed our relationship dramatically". Another ones opinion was "I had talk with my husband about sexual issue but my husband would always just say it doesn't make any difference, but I know deep down that it did". It was stated by one participant that 'I never had sex again after the injury. I don't feel any sexual desire. My husband was not interested to have sex with me". Another ones opinion was "I was depressed because my husband would go out. Eventually I couldn't take it anymore but I didn't want divorce".

Loss of self-identity $(\mathrm{n}=12,100 \%)$

Almost everyone (12) thought that they have lost their selfidentity. Before the injury all of them were housewives. They had their own identity at their family. But now they are living at their father's family. If they were not injured they would have family and self-identification. One of the participants said that 'I can't walk. I can't do house hold activities. I have lost my confidence. Before my injury, I was house wife. But now I don't have any identification".

One expressed like that "after my injury I am a valueless person in my family. Now I have not any identification. Spinal cord injury have taken everything from me even it take my identification also". It was stated by one participant that "I was really depressed after my injury..... It seems like I lost my identity".

\section{Loss of intimacy with laws family $(n=8,66.67 \%)$}

Among the12 respondents, two third participants (8) gave blame to their in laws. They told their in-laws family was against to their marital relationship. In-Laws were influence their husband to divorce them or stay separate from them. One participant expressed that "I was depressed because my husband would go out to other girl. Eventually, I couldn't take it anymore. He had got support from his family regarding this issue. Sometimes, I was trying to talk with him in this issue. But he ignored me, and he said that he did not want me more". It was stated by one participant that "his family was always influenced him to divorce me and get married again". Other one said "after my SCI, everything became changed. My life style, activities, family and friends everything became change. Yes, everything got more difficult in every way! My husband did not want to live with me and his family also did not want me. It was expressed by my husband was very good and wanted to live with me. But my mother in law did not want that her son to live with me. She thought that I am a disable woman and I am not able to do anything. Had got this from one participant when I was admitted in CRP and my husband heard that, I will be not able to walk again, he didn't come to meet me again. I was trying several times to talk with him, but he ignored me".

Loss of autonomy $(n=12,100 \%)$

Every respondent (12) thinks that because of SCI, they lost their autonomy and it is also responsible for their marital disharmony. One woman said that "I have to depend on others. I can't even reach out and continue higher function without others support. So that my husband had considered me as burden. One person stated that I am a paralyzed parson. I have not any independent function. I think that it is another reason of our Separation". One participant expressed that "I am disable person and I am also dependent on my family member and on my wheelchair. To perform my most of the function, I have to depend on other so that my lows family now does not like me".

\section{Impact on Relationship with Family Member}

With whom live $(\mathrm{n}=12,100 \%)$

Every participant (12) was living with her parents' house. No one lives independently or with laws family. One person said that "I am living with my parents. But my brother is the key person of my family". One person stated that "I wanted to live with my In-laws home. But they made me bound to leave their place". Had got this from one participant "in our country it is not possible to live with In-laws family after divorce. So I had no other option to live other place except my family'.

\section{Support from family $(\mathrm{n}=7,58.33 \%)$}

Among the 12 participants, 7 respondents thought that they deserve more decent attitude from their family. Only two participants think that their family members' attitudes are tolerable and three participants were satisfied towards their family member's attitude. One person said that "the attitudes of my family members are very supportive. They are always ready to help me and fulfill my requirements. It was expressed by the main factor that helped me was my family... They helped me a lot!" Had got this from one participant "what helped me the most in adjusting after the injury was my family".

\section{Nutrition $(n=4,33.33 \%)$}

Only one third of participants (4) were satisfied about their nutrition. But rests of the participants were not satisfied. All the participants were depended on their family members for their nutrition.

It was expressed that "I have severe constipation. 
Sometimes, it was not possible to arrange extra vegetable for me. That time I feel it is not my home". One was stated that "some of my family members are very positive towards my food but some of are very careless. They consider me as a burden". Had gotten from one participant was that "I am not worried about my nutrition. I am satisfied though I know that it is not sufficient for me". Another one said that "it is not possible to express my choice about my food. They will be bothered if I tell something. Generally they think I am a burden at their family. My sister-in-law always tells that type of things".

\section{Role as a Decision maker $(n=11,91.67 \%)$}

Most of the participants (11) depend on their family member to take any decision. Even they cannot fulfill their tiny wishes without family support. They have to take decision from their family member about what they want to do or where they want to go even what they want to eat. They have to depend on their family member in case of every situation. Eight participants think that now a days they are more dependent on their family because of their divorce.

\section{Impact on Social Participation}

\section{Relationships with community people $(n=4,33.33 \%)$}

On average, respondents were not satisfied with the support; they received from other community people. A higher proportion of respondents who lived in society were not satisfied with the community people. One third participants (4) think that community people always try to make them belittle them. One third participants were not feeling comfortable with others in community. One of the participant said that "If I went to participate any social program, they always isolated me....they gave me a separated space". Stated by one was "Most of the time they (community people) asked me lots of question about my disease and also causes of separation which make me very embarrassed".

\section{Acceptance at social activities $(n=4,33.33 \%)$}

One third participants (4) were not satisfied about their acceptance in community. Nevertheless, rests of the participants blamed themselves. They were not interested to participate any of the social activities like wedding ceremony, birthday party, funeral program, voting, and any sports and so on. Stated by one was "if I went to join any social activities everyone asked several questions. It is really nagging for me. This type of question I really don't like". Another one said that "I don't like to go any program. Even I don't want to go any relative's house. My husband was always with me before my injury. Now I feel alone if I want to go anywhere". Had gotten from one participant that "It is not easy to go any program in my community. The place, accessible road, peoples attitude nothing is not suitable for me. So that I had not attend any social or family program". Another one said that "some people showed excessive sympathy towards me because I am disable person as well wheelchair user".

Impact on productive activities
Most of them are unemployed except one participant. All of them are said that getting a job or again start education is very challenging after injury without husband.

\section{Nature of problem $(n=12,100 \%)$}

Everyone thinks that if their husband would beside of them they will get more benefits from everywhere. All of them are now live with their own maternal house. So it was really difficult to start anything from the beginning. Everyone thought that they have less opportunity to do anything. One participant said that "I have no opportunity to start anything from the beginning. To start anything new, I need money. But my family does not have enough money for me". One was also said that "I was tried to start a small business. Unfortunately, my family was not supportive. They think that I will not able to do any earning related activities". Another one said that "I did not get any financial compensation from my husband".

\section{Financial worries $(11,91.67 \%)$}

Only one participant was involved with employment. No one got financial support from the government or their "ex" husband. The women indicated that they already have trouble to manage the basic needs with living with a disability. They were very aware of the current economic reductions. Stated by one was "I haven't any saving money. My husband did not give me any money. I have no work. Sometimes it makes me worries". Another participant said that "I did not get any compensation after my separation. Sometimes I think what will be happen after my parent's death". It was expressed by one was "I got only 50000tk after my divorce. It is very less amount money. I have already expended 30000 tk. And my brother took rest of the money. I am worried about my future".

Fear of increased dependency and isolation $(n=12,100 \%)$

This was common, particularly the fear of having to leave their in-law's home and be placed' in a maternal home. Almost all of them (12) expressed a profound sense of helplessness and uncertainty about the future after divorce and separation. One them stated "I'm afraid when I think about my future. Now I am dependent on my family. But if my parents died, I will be isolated. One was said "My husband had abandoned me. I have no kids, no work. I will be alone after my parent's death. One participant said that I don't feel ok in front of others because I am a disable and my husband had gone. So that I didn't try for any work".

\section{Physical environment $(\mathrm{n}=12,100 \%)$}

All of them were wanted to modify their physical environment but unable to do so as because financial burden. They were wish the support from their husband. One of the participant said that "I want to start a small business like swing. I want to open a shop in front of my house. I need some home modification. But my brother was not helpful if my husband had present then it became possible". Stated by 
other one was "if I want to do any work, I need money, ramp, good road etc. who will do this for me?

Loss of future, dreams $(n=12,100 \%)$

Almost everyone was so much depressed thinking about their future as because they were separated and fear about how they contribute their family now. One was stated that "I had my own family, husband and daughter. Now I have nothing. I have lost everything because of my injury". Another one said that "After my injury I had lost everything. Even now I had no way of earning. What will be happen in the future I don't know".

\section{DISCUSSION}

In this study the ratio of tetraplegia and paraplegia was $37.32 \%$ and $22.03 \%$. The research was done by [14] and he also showed that $51.9 \%$ had the diagnosis of traumatic paraplegia and $42.6 \%$ had traumatic tetraplegia. The divorce or separation rate was $22.03 \%$ where another study was support this statement. That study reported the divorce rate $8 \%$ to $48 \%$ [12]. Majority of the participants $(64.1 \%)$ were within the range of years of age 27-37 years where another study showed that $49.7 \%$ participants were within the range of 3rd decade. In this study it was showed that almost half of the participants were illiterate. College graduates were significantly less likely to get divorced [15]. The divorce rate was 1.85 times higher among persons without college educations [15]. Higher education was significantly related to community integration [16].

About the three fourth participants were unemployed. One of the benefits of occupation is help to enhance community integration [17]. One of the articles found that social, cultural, and environmental barriers reduced participation of vocational activities. The monthly income of the participants including other family members was very low. Almost $65 \%$ had monthly income within 5000 tk. But according to [16], $67 \%$ had a monthly income below 10,000 Taka and it was really very unfortunate. The causes of low income ware identified by one study. Almost two third participants (74\%) were from rural area. $69.2 \%$ SCI patients [14] were from village. The highest divorce or separation was seen on within the 3-4 years of injury and it was about $40 \%$. During the first 5 years after marriage onset the number of divorces was 1.7 times higher than expected [15]. In general the impact of SCI on marriage was not good. The percentage of post injury marriage is lower than pre injury marriage [15]. More than half of the divorced or separated women had no child. Divorce my varied according to number of children [12]. More than half of the divorced or separated women were diagnosed as complete paraplegia. Higher number of people with complete spinal cord injury evident by category A in ASIA scale was noted as 59.8\% respondents [14]. Although there were parallel relationships between demographic variables of age and neurologic group, neither these factors nor duration of injury appeared to impact change in community reintegration. More significant was the relationship between perceived life satisfaction and community integration [12]. The biggest difference in divorce rates were varied when persons with neurologically incomplete motor functional injuries were compared with all other persons [15]. It was also recommended that the community integration is poor for the women with divorced and separation with SCI. if CIQ-R score is poor then it could be said that community integration is also poor. Level of community integration depends on score of CIQ-R [18]. The total community integration score of mean and SD was $12.03 \pm 3.87$ which was recommend that it was really poor. There was a study in Bangladesh conducted by [16], stated with the total community integration score of mean and SD was $15.09 \pm 3.4$ and women should have reported low total community integration scores [16].

There was overall satisfaction with access to community buildings (mean score range, 6.9-8.5; where 10 is most satisfied) [19]. The participants did not score high in home (2.89) and productive integration (3.12) subscales when compared with other study [16]. Independent living or reduced dependency on others in one's residence is difficult in Bangladesh as most of the individuals with SCI do not have access to disability friendly residences. In the absence of this, individuals require manual assistance from others for transferring from bed to wheelchair, using toilets, and wearing [16]. Such assistance is not often readily available to them and could perhaps be one reason for scoring low in home integration subscale. Another reason might be culture specific - as women in this society in general are expected to perform many household activities such as preparing meals, providing childcare and other day to day household works. On the other hand male are not involve in this type of activities [16]. The participants scored low (3.74) in social integration subscale suggesting either they were not able to maintain previous social network or created new networks possibly with other individuals with similar injury experience because of a loss of previous relationships. On the other hand, one of the study was done by [16] stated with the participants scored high (7.21) in social integration subscale which indicates for higher community integration on social participation. Finding employment is barely possible after spinal cord injury in Bangladesh [16]. The lower level of educational attainment and an absence of adequate vocational training for the individuals with women in this country further complicate the process of productive integration. This was also supported by [16] findings. More than one third of the participants reported unavailability of appropriate jobs that they could do with their disability. Therefore, $t$ individuals with SCI often lose their autonomy in making decisions related to finance [16]. The subscales of community integration include items such as - ability to prepare meals and employment status, are closely linked with immediate survival of individuals with SCI in the context of Bangladesh [16].

The objectives of the study were to understand the perception about the consequences of divorce and separation in community reintegration. Table 2 are listed the most common themes based on fulfill the objectives. The most commonly mentioned theme is listed here. This qualitative study generated several important findings. First the women had described the causes of divorce and separation after SCI. From the participants researcher got five main causes like loss of autonomy and functional ability, loss of sex life, loss of self-identity, loss of autonomy, and loss of intimacy with in 
laws. Lack of physical fitness, social skills, financial support are the responsible causes that fail to provide sufficient satisfaction for the marriage to survive [15]. Almost every participant thinks that the main reasons of their marital disharmony are loss of anatomy and lessen function ability. Participants were thought that loss of sensation, unable to move legs, unable to control bowel bladder movement were the main physical impairment of divorce or separation after SCI. According to the [7] statement, individual's capacity and mobility impairment has a great effect on individual's relationship. There are some other hidden causes such as bladder, bowel, and sexual dysfunction, and secondary health conditions which can have a negative impact on relationship.

Most of the participants had given priority about sexual life in conjugal life. However, most of them had not any experience of having sex and willingness to having sex of their husbands with them. Sexual life is changed after SCI which may be barriers to sexual intimacy and affected many aspects of person's sexuality negative [12]. SCI women are frequently rejected by men. However sexual life is very important component of conjugal relationship [7], [12]. Almost everyone lost their confidence. They were depressed about their condition. They were also not confident about their relationship. A study on long-term quality of life in married life found that severely injured persons reported more depression, confusion and overall mood disturbance which had a bad impact on marital status [12]. There is a chance of divorce if intimate relationship does not build up at the time of the injury among couple. There is also opportunity for developing intimate relationships may be hampered by lack of peer acceptance in the community as well as lack of self-condense [12].

Among the participants, two third participants gave blame to their in-laws for their divorce or separation. Their opinion is like that, their husband was good but in-laws family member was not good. They didn't want their relationship with husband. According to [20] statement, long term marital stability, satisfaction, and commitment over time not only depends on husband. It also depends on in the relationship with in-laws. All of the participants thought that, they have lost their autonomy and they are now dependent to other. Moreover, they believe that dependency is the another important cause of their divorce and separation. Person becomes high level of dependent after SCI. That time couples are under extreme pressure to adapt and cope following the injury. As a result divorce ad separation can lead after injury [12].

Every respondent was living with their own parent's house. According to [21], SCI patients usually live in a community with close family members and they are also act as primary caregiver. However, care giving family members has a crucial importance in the adjustment of the patient with SCI.

Some of participant was not satisfied toward their family member's attitude. In our country, women were back to their parents' house after divorce. However, in western country young unmarried SCI patients usually live with their parents. Family relationships strongly influence life satisfaction of people with spinal cord injury. Only 35\% SCI patients got help and support from family their members and friends [19]. Without supportive relationship with family member it would difficult for these people to fully engage in the community participation [19].

Participants were not satisfied about their nutrition. Nutrition is an important element for SCI to keep allied health. The requirements of nutrition for the SCI individuals based upon their unique physiology. Female subjects had more nutritional deficiencies and on nutritional risk [22].

Every family member had to depend on take any decision even though for any tiny things. One of the study done by Carpenter among a large number of respondent about their joys and achievements, and decision making, or to ask for assistance when required. They said that they were ignored during any decision making procedure in family [19]. After divorce or separation sometimes ensuring social participation became more difficult due to some causes like lack of intimacy with community people, Recognition, lack of acceptance at social activities, not involve with decision making. According to [12], social relationship is not only breakdown due to personal handicapping but also influenced by individual's value system. According to [19] social participation depends on involvement with society people, organizing and participation on social events. One of the turkey study showed that social participation will be hampered due to attitudinal barrier [23]. Most of the participants were experienced barrier during social event participation where no limitations were experienced by $18.5 \%$ of the respondents [23]. Impact on social participation observed attitudinal barriers as a result of the limitations and prejudices imposed by SCI. The authors found that most women with SCI, specifically paraplegia, have difficulty in understanding and articulating their feelings about their bodies after the injury because they feel unattractive. This is due to low self-esteem and self-discrimination, evident in their fear of sexual frustration as a result of their physical condition, characterized as abnormal and disabled. In terms of sexuality related specifically to the sexual act, participants emphasized their fear of being intimate with their partners [26]. One third participants were not satisfied about their acceptance in community. It was found that greater levels of social support and peer mentoring can improve long term outcome of SCI [24]. Greater life satisfaction has been documented when people with SCI were involved in productive activities, such as work, leisure, and education 8 is associated with community reintegration [19]. Women with disabilities have less the financial support and it have been increasing with the age of the women. The women indicate that they already have trouble managing the extra expenses associated with living with a disability [25]. In general, persons with SCI were satisfied with their lives but when reduced quality of life was identified it was particularly related to unsatisfactory work and leisure situations [25]. In this study some physical environment also makes hampered on productive activities. Environmental factors [19] were critical determinants of societal participation (compared with personal factors, impairments, and activity limitations) but were more strongly related to life satisfaction.

\section{CONCLUSION}

Community reintegration dropped with divorce and separation in this sample of Bangladesh individuals' women 
with divorce and separation with SCI. Partner relationships seem to be affected by a SCI, although not as much as is widely believed. This study has identified several areas that should be addressed to improve in community integration. The reasons which were responsible to decline community integration after divorce or separation was find out by this study. This study provides a rich description of the multidimensional nature of divorce or separation and its impact on community integration as identified by women with SCI living in the community.

\section{ETHICAL CONSIDERATION}

Ethical permission was obtain from Institutional review Board (IRB) of Bangladesh Health Professions Institute (BHPI) before conducting this research. Also for demographic data permission were received from the Head of Medical Service Wings of Centre for the Rehabilitation of the Paralyzed (CRP). After obtaining permission initial data for demographic information were collected from nursing department.

\section{FUND}

This was self-funded research.

\section{REFERENCES}

[1] Simão A, Pereira A. Individuals with Spinal Cord Injury in Rehabilitation: Quality of Life Study. Open Journal of Medical Psychology. 2017;06(02):66-75. Doi: 10.4236/ojmp.2017.62005.

[2] Kreuter M. Spinal cord injury and partner relationships. Spinal Cord. 2000;38(1):2-6. Doi: 10.1038/sj.sc.3100933.

[3] Kreuter M, Sullivan M, Dahllöf A, Siösteen A. Partner relationships, functioning, mood and global quality of life in persons with spinal cord injury and traumatic brain injury. Spinal Cord. 1998;36(4):252-261. DOI: $10.1038 /$ sj.sc. 3100592.

[4] Ahmed N, Quadir M, Rahman M, Alamgir H. Community integration and life satisfaction among individuals with spinal cord injury living in the community after receiving institutional care in Bangladesh. Disability and Rehabilitation. 2017;40(9):1033-1040. Doi: 10.1080/09638288.2017.1283713.

[5] Lee B, Cripps R, Fitzharris M, Wing P. The global map for traumatic spinal cord injury epidemiology: update 2011, global incidence rate. Spinal Cord. 2013;52(2):110-116. Doi: 10.1038/sc.2012.158.

[6] DeVivo M, Hawkins L, Scott Richards J, Go B. Outcomes of postspinal cord injury marriages. Archives of Physical Medicine and Rehabilitation. 1994;75(6):718-719. Doi: 10.1016/00039993(94)90208-9.

[7] Amsters D, Schuurs S, Pershouse K, Power B, Harestad Y, Kendall M et al. Factors Which Facilitate or Impede Interpersonal Interactions and Relationships after Spinal Cord Injury: A Scoping Review with Suggestions for Rehabilitation. Rehabilitation Research and Practice. 2016; 2016:1-13. Doi: 10.1155/2016/9373786.

[8] Merghati-Khoei E, Maasoumi R, Zarei F, Laleh L, Pasha Y, Korte J et al. How Do Iranian People with Spinal Cord Injury Understand Marriage? Topics in Spinal Cord Injury Rehabilitation. 2017;23(1):7177. Doi: $10.1310 /$ sci2301-71.

[9] Khoi EM, Latifi S, Rahdari F, Shakeri H, Arman F, Koushki D, Javidan AN, Otaghsara SM. The effect of injury-related characteristics on changes in marital status after spinal cord injury. Iranian journal of public health. 2015 Oct;44(10):1395.

[10] DeVivo MJ, Fine PR. Spinal cord injury: its short-term impact on marital status. Archives of physical medicine and rehabilitation. 1985 Aug 1;66(8):501-4.

[11] Kaya H, Yurtseven Ç. Can Marriage be Bad for Health? Evidence from Turkey. Economics \& Sociology. 2016;9(1):162-172. Doi: 10.14254/2071-789x.2016/9-1/11.
[12] Kreuter M, Taft C, Siösteen A, Biering-Sørensen F. Women's sexual functioning and sex life after spinal cord injury. Spinal Cord. 2010;49(1):154-160. Doi: 10.1038/sc.2010.51.

[13] [13] SPSS Inc. Released 2007. SPSS for Windows, Version 16.0. Chicago, SPSS Inc.

[14] Rahman A, Ahmed S, Sultana R, Taoheed F, Andalib A, Yasir Arafat S. Epidemiology of Spinal Cord Injury in Bangladesh: A Five Year Observation from a Rehabilitation Center. Journal of Spine. 2017;06(02). Doi: 10.4172/2165-7939.1000367.

[15] DeVivo M. Epidemiology of traumatic spinal cord injury: trends and future implications. Spinal Cord. 2012;50(5):365-372. Doi: 10.1038/sc.2011.178.

[16] Ahmed N, Quadir M, Rahman M, Alamgir H. Community integration and life satisfaction among individuals with spinal cord injury living in the community after receiving institutional care in Bangladesh. Disability and Rehabilitation. 2017;40(9):1033-1040. Doi 10.1080/09638288.2017.1283713.

[17] Fleming J, Doig E, Katz N. Beyond Dressing and Driving: Using Occupation to Facilitate Community Integration in Neurorehabilitation. Brain Impairment. 2000;1(2):141-150. Doi: 10.1375/brim.1.2.141.

[18] Willer B, Callaway L, Tippett A, Herd N. Modification of the CIQ Including Assessment of Technology Use and Development of Population Norms. Archives of Physical Medicine and Rehabilitation. 2014;95(10):e85. Doi: 10.1016/j.apmr.2014.07.281.

[19] Carpenter C, Forwell S, Jongbloed L, Backman C. Community Participation After Spinal Cord Injury. Archives of Physical Medicine and Rehabilitation. 2007;88(4):427-433. Doi: 10.1016/j.apmr.2006.12.043.

[20] Bryant CM, Conger RD, Meehan JM. The influence of in-laws on change in marital success. Journal of Marriage and Family. 2001 Aug;63(3):614-26.

[21] Ünalan H, Gençosmanoğlu B, Akgün K, Karamehmetoğlu Ş, Tuna H, Önes K, Rahimpenah A, Uzun E, Tüzün F. Quality of life of primary caregivers of spinal cord injury survivors living in the community: controlled study with short form-36 questionnaire. Spinal cord. 2001 Jun;39(6):318-22.

[22] Levine A, Nash M, Green B, Shea J, Aronica M. An examination of dietary intakes and nutritional status of chronic healthy spinal cord injured individuals. Spinal Cord. 1992;30(12):880-889. Doi: $10.1038 /$ sc. 1992.165 .

[23] Dijkers M. Community Integration: Conceptual Issues and Measurement Approaches in Rehabilitation Research. Topics in Spinal Cord Injury Rehabilitation. 1998;4(1):1-15. Doi: 10.1310/bjja-2018$45 \mathrm{kl}-0 \mathrm{vtl}$.

[24] Callaway L, Enticott J, Farnworth L, McDonald R, Migliorini C, Willer B. Community integration outcomes of people with spinal cord injury and multiple matched controls: A pilot study. Australian Occupational Therapy Journal. 2016;64(3):226-234. Doi: 10.1111/1440-1630.12350.

[25] Pentland W, Walker J, Minnes P, Tremblay M, Brouwer B, Gould M. Women with spinal cord injury and the impact of aging. Spinal Cord. 2002;40(8):374-387. 10.1038/sj.sc.3101295.

[26] Barclay L, McDonald R, Lentin P. Social and community participation following spinal cord injury. International Journal of Rehabilitation Research. 2015;38(1):1-19. Doi: 10.1097/mrr.0000000000000085. 